\title{
WPS4528
}

\author{
Policy Research Working Paper 4528
}

\section{Does Poverty Research in Russia Follow The Scientific Method?}

\author{
Michael Lokshin
}

The World Bank

Development Research Group

Poverty Team

February 2008 
Policy Research Working Paper 4528

\begin{abstract}
This paper presents the first critical review of literature on poverty published in Russia between 1992 and 2006. Using a dataset of about 250 publications in Russian scientific journals, the authors assess whether the poverty research in Russia satisfies the general criteria of a scientific publication and if such studies could provide reliable guidance to the Russian government as it maps
\end{abstract}

out its anti-poverty policies. The findings indicate that only a small proportion of papers on poverty published in Russia in 1992-2006 follow the universally-recognized principles of the scientific method. The utility of policy advice based on such research is questionable. The authors also suggest steps that could, in their view, improve the quality of poverty research in Russia.

This paper-a product of the Poverty Team, Development Research Group-is part of a larger effort in the department to improve the standards of economic research in the client countries. Policy Research Working Papers are also posted on the Web at http://econ.worldbank.org. The author may be contacted at mlokshin@worldbank.org.

The Policy Research Working Paper Series disseminates the findings of work in progress to encourage the exchange of ideas about development issues. An objective of the series is to get the findings out quickly, even if the presentations are less than fully polished. The papers carry the names of the authors and should be cited accordingly. The findings, interpretations, and conclusions expressed in this paper are entirely those of the authors. They do not necessarily represent the views of the International Bank for Reconstruction and Development/World Bank and its affiliated organizations, or those of the Executive Directors of the World Bank or the governments they represent. 


\title{
DOES POVERTY RESEARCH IN RUSSIA FOLLOW THE SCIENTIFIC METHOD?
}

\author{
Michael Lokshin* \\ Development Research Group, World Bank \\ 1818 H Street NW, Washington DC, 20433 USA
}

* Address for correspondence: Michael Lokshin, Development Research Group, World Bank, 1818 H Street NW, MC3-306, Washington DC, 20433, USA. Email: mlokshin@worldbank.org.

Anna Luk'yanova provided invaluable contributions to this research. The author is grateful to Ruslan Yemtsov, Rostislav Kapelushnikov, Vladimir Gimpelson and Salman Zaidi for their comments and suggestions.

The findings, interpretations and conclusions of this paper are those of the author and should not be attributed to the World Bank, its Executive Directors, or the countries they represent. 


\section{Introduction}

Poverty is a central issue for Russian policymakers who view poverty reduction as a cornerstone of the nation's economic development strategy. Despite a significant decline in poverty over the last decade, the slowing economic growth and a regionally unbalanced pattern of development indicate that poverty will pose major policy challenges in Russia for years to come. To rise to those challenges, the Russian government would need reforms in many areas related to poverty reduction, including the system of social protection and labor market policies (World Bank 2005). Such reforms should be designed based on an extensive analysis of characteristics of poverty, the relationship of poverty and economic development, and poverty dynamics. The success of reforms would depend on the quality of such research.

The history of poverty studies in Russia dates back to the 1920s when the minimum consumer budget, or subsistence minimum, was established by a government decree and was calculated on a yearly basis for several years before being abolished by Stalin (Pisarev 1957). During the Soviet period, the concept of poverty was unacceptable for ideological reasons. However the idea of maintaining a minimum standard of living for the population existed as early as in the 1970s. A minimum consumption basket was developed in the 1970s as a guide for establishing the minimal standard of living for the Soviet population. The conventional, need-based concept of poverty did not gain acceptance in the Soviet Union until the late 1980s (Klugman 1997). In the early 1990s, the Russian government adopted a new food basket (Popkin, Mozhina, and Butrin 1992) and a new poverty line. Russia's official poverty lines were established under guidelines developed by the Ministry of Labor and Social Development (MLSD, 2000).

Since 1992, Russian social science has witnessed a sharp increase in the number of studies attempting to devise methods to determine poverty lines, describe poverty profiles, and analyze poverty causes. The community of poverty researchers, too, has been growing and, as we show in this paper, while being dominated by economists and sociologists, includes scientists from other fields with different approaches toward the direction and methodology of scientific studies. This diversity of perspectives might be important for a comprehensive analysis of poverty but it could complicate the 
development of standards and criteria governing the quality of research in this new - for Russia - field.

The notion of poverty is constantly changing, evolving and can be understood very differently by various individuals and agencies. The progress of poverty research is affected, among other things, by what is a hotly-debated and politically sensitive concept of poverty. In many instances, subjective values play a critical role in the direction of such research. The prevailing social ideas influence the ways research questions are formulated, poverty analysis is conducted, and how research findings are implemented in practice. In many cases, government interventions aimed at poverty reduction are not motivated by the scientific results, but arise from ideology and societal perceptions of social justice.

It is often difficult for the general public and policy makers to clearly distinguish between high quality studies and studies of mediocre quality given the multiplicity of factors affecting poverty dynamics in a country. In that situation, self-regulating norms developed within the research community are crucial for the progress of the scientific knowledge. Studies which synthesize knowledge across several avenues of research are instrumental in reaching scientific consensus and pushing the boundaries of scientific knowledge. While about 300 poverty-related scientific papers were published in Russia in 1992-2006, we are unaware of any single study that summarizes and evaluates this vast body of literature.

This paper presents the first critical review of poverty research in Russia. Rather than focus on the actual findings, as it is often done in meta-analysis, we review the formal methodological approaches to poverty research applied by Russian scientists. Are studies of poverty in Russia conducted according to the general principles that are common across all areas of empirical scientific research and that guide natural and social science? Do studies on poverty in Russia provide objective, reliable data to inform design and evaluation of policy interventions?

As it seeks to answer this question and following the general principals of the scientific method, the next section describes the data we have used for this meta-analysis. Section 3 presents general principles of the modern scientific method. A discussion of the 
main results is provided in section 4 . Section 5 offers policy recommendations and conclusions.

\section{Data}

Our analysis is based on 250 articles published in Russian scientific journals over the last 15 years by 188 Russian scientists ${ }^{1}$. While this collection of papers may not be exhaustive, it is representative of the majority of publications related to poverty in Russia. Since 1992, the number of papers focusing on poverty has been increasing and reached a plateau of about 21 publications per year in 2000-2006 (Figure 1). More than 80 percent of all studies on poverty were conducted in the fields of economics and economic sociology, with the rest attributed to sociology and social policy.

Moscow-based scientists authored most publications on poverty in Russia (70 percent of publications), followed by their colleagues from Novosibirsk and SaintPetersburg (4 percent each), and Saratov (3 percent), see Table 2. The journal Sociologicheskie Issledovaniya (Sociological Research) published 42 papers, or 17 percent of the total number of publications, the journal Narodonaselinie (Population) published 32 papers (13 percent), and the journal Monitoring Obshestvennogo Mneniya (Monitor of Public Opinion), 26 papers (11 percent). Each of Obshestvo i Economica (Society and Economics), Economist (Economist), Problemu Prognozirovaniay (Problems of Economic Forecasting), Voprosy Economiki (Economic Matters), Obshestvennue Nauki i Sovremennost (Social Sciences and Modern Times), and Mir Rossii (Russian World) published about 15 papers on poverty (see Table 1 in Appendix).

The distribution of articles by authors is typical of scientific publications: while seven researchers (less than 4 percent of all authors) published more than a quarter of all articles, 135 researchers produced only one publication each (Table 1). Among the most productive, our database contains 13 publications by Rimashevskaya, 11 publications by Tapilina, and 9 publications each by Ovcharova and Taksanbaeva. Forty-seven percent of the authors in our database are PhD's, 23 percent hold a second level (Habilitation)

\footnotetext{
${ }^{1}$ See Appendix for a complete list of publications used for the analysis in this paper.
} 
doctorate degree $^{2}, 16$ percent have no degree, and we were not able to determine the degrees held by about 15 percent of the authors. Economists and sociologists dominate poverty research in Russia, but contributions to the literature on poverty have been and continue to be made by psychologists, philosophers, historians and even biologists.

\section{Scientific method}

The scientific method is a body of techniques for investigating phenomena and acquiring new knowledge, as well as for correcting and interpreting previous knowledge. The scientific method is based on collecting empirical, measurable evidence subject to specific principles of reasoning.

The main principles of the scientific method were outlined by Bacon in Novum Organum published in 1620. The inductive empirical method employed by Newton formed the basis of the bulk of scientific inquiries in the $18^{\text {th }}$ and $19^{\text {th }}$ centuries. Mill's System of Logic (1843) systematized Newton's approach, offering five explicit statements on building a scientific hypothesis. The modern scientific methods are influenced by the works of Peirce (1878) who devised a hypothesis-testing technique based on a combination of deduction and induction. John Dewey (1938) postulates that any scientific theory, hypothesis, or judgment should be supported by measurements and empirical results, observational data, and by mathematical and logical analysis. Karl Popper (1959) argued that scientific theories can and should be rationally criticized and should be subjected to tests that may invalidate them. According to Popper, the scientific communities should be open to a free exchange of critical comments.

Modern scientific research builds understanding of the phenomenon in the form of models and theories that can be tested. Although procedures might vary for different fields, all branches of modern science share the features of scientific investigation by relying on methods that could be viewed as a series of the following steps or guiding principles:

1. Define an important question that can be investigated empirically.

\footnotetext{
${ }^{2}$ Russian academic system is similar to the German system that requires a post-doctoral thesis produced and defended in order to qualify for teaching graduate students and $\mathrm{PhD}$-students and to attain professorship.
} 
2. Review the existing information on that question, linking the research to the relevant literature.

3. Form a hypothesis and predictions (theoretical, hypothetical explanation for the question of interest).

4. Collect and analyze data. Use methods that permit direct investigation of the question.

5. Interpret the results and draw conclusions.

In a similar spirit, Frisch (1933), in his foreword to the first issue of Econometrica, suggests the following principles of presenting empirical economic work: "In statistical and other numerical work presented in Econometrica the original raw data will, as a rule, be published, ... . This is important in order to stimulate criticism, control, and further studies. The aim will be to present this kind of paper in a condensed form. Brief, precise descriptions of (1) the theoretical setting, (2) the data, (3) the method, and (4) the results, are the essentials."

These principles absorb the experience of generations of researchers who continually developed their methods and theories in a quest for objective and rigorous knowledge. The scientific community uses these principles as standards by which to conduct scientific research with an emphasis on objectivity, rigorous reasoning, and thorough and honest reporting (Ziman 2000). Social research and research on poverty is often conducted using quantitative or qualitative methods, or a combination of both. While these two approaches might use different assumptions and different modes of inquiry, epistemologically, qualitative and quantitative approaches are similar (Campbel 1974) and share the same "logic of inference" which is summarized in the scientific method (King et al. 1994).

In early 1930s, the Soviet Government initiated a move to replace supposedly bourgeois methods of traditional economics with the political economy of socialism. This change caused Soviet social scientists to reject the scientific method. The system of political economy was based on the conceptual framework of so-called "historical materialism" which emphasized descriptive research and was completely devoid of mathematically-intensive behavioral modeling universally applied by Western 
economists (Alexeev et al. 1992). The mathematical economics (called economic cybernetics) that emerged in the late 1950s in the USSR consisted in regrouping elements of control and information theory relevant to socialist planning (Lange 1970). It focused on the economics of central planning and state-owned enterprises and relied on the methods of linear programming and optimization techniques of socialist production (Brue and MacPhee 1995). The paramount task of the Soviet economics was to provide a scientific basis for the policies of the Soviet Communist Party. Soviet economists had very little interaction with Western colleagues. A limited number of copies of a heavilyedited and censored translation of Samuelson's Economics was published in Moscow in 1966 to be used only for "research" purposes (Gerschenkron 1978), and no translations of significant works in economics were published in the Soviet Union up until the late 1980s.

The collapse of the Soviet Union was followed by a rapid transformation of the system of Russian economic thought and economic education (Kovzik and Watts 2001). Russian universities began reforming their curricula by introducing courses on market economics $^{3}$. Different fields of economics were reformed at a different pace. Poverty research, completely neglected in the Soviet era, lacked the negative heritage of Marxist ideology. As they entered this, new for Russia, field, Russian scientists could rely directly on the methodology of a fully-developed research discipline, strictly adhering to the principles of scientific methods. Have they utilized this opportunity to break out from the past? The next section provides an answer.

\section{Do poverty studies in Russia follow the general principles of scientific method?}

We believe that any study of poverty: quantitative or qualitative, causal or descriptive, economic, sociological or even philosophical can and should be pursued rigorously. The relative weights of components of the scientific method will be different for different forms of inquiry. Empirical economic studies of poverty might put more emphasis on strong theoretical models and econometric techniques of analysis of large random

\footnotetext{
${ }^{3}$ The Russian edition of the principles of economics textbooks in macro and micro-economics were published in Russia with a circulation of more than 500,000 copies in 1992 (McConnell and Brue 1992). These volumes became the leading textbooks for economic courses throughout Russia.
} 
samples. Sociological poverty research can rely on smaller, focused samples, and use different methods of data analysis and hypothesis testing. But regardless of the field, any poverty research should employ the scientific method in formulating the research question, linking the question to the relevant literature, gathering data, proposing hypotheses, and testing such hypotheses in the formulation of theories. This section discusses the main steps involved in the modern scientific research and assesses whether poverty studies published over the last 15 years in Russia follow the basic principles of the scientific method.

\section{Research question}

Any research should be motivated by a question and the success of a scientific study depends on the quality of the research question. As Einstein and Infeld (1938) note, “The formulation of a problem is often more essential than its solution, ... To raise new questions, new possibilities, to regard old question from a new angle requires creative imagination and marks real advance in science.” Research questions are posted to solve a problem, to describe or determine the causes of a certain phenomenon. They can also arise from practice (Stokes 1997). A question determines what methods are used to look for answers. A research question should be worded in such a way that the adequacy of alternative hypothesis could be tested. The significance of a research question is determined with reference to previous research and theories and whether a posed question is relevant for practical issues. Scientific knowledge, of course, evolves by virtue of incorporating new work into the body of research that has come before it.

The objective of science is to solve problems - that is, to provide "acceptable answers to interesting questions" (Laudan 1977, p 13). Broadly speaking, scientific questions could be categorized into the descriptive, causal and the questions that try to explain the causal mechanism. Descriptive questions provide quantitative measures of certain phenomena or their changes. Papers describing poverty incidence and poverty profiles provide answers to that type of question. Causal questions focus on the causal relation between two phenomena: Did A cause B? In poverty studies, these questions could be: Does the education level of a household head affect the poverty status of the 
household? What is the effect of female labor force participation on household consumption? Finally, scientific questions can be formulated to explain the mechanism that creates the causal effect.

Despite the importance of a research question for any scientific study, more than 60 percent of the papers we reviewed lack a clearly defined research question. The papers jump directly into the presenting some numbers or into a discussion of different issues without specifying the main purpose of their analysis. Among the works that do formulate a research question, most studies offer a descriptive analysis of poverty. Almost none of the studies investigate the causal mechanisms behind observed poverty outcomes, such as different factors and characteristics which affect household welfare.

\section{Review of relevant literature}

Before undertaking a scientific investigation it is crucial to find out whether a particular question has perhaps been answered before. This can be accomplished via a review of previous works relevant to a particular problem. A review of literature can also reveal known facts and enable comparison of new findings with previous ones, helping generate new and/or modify existing results. A review of previous studies on a topic informs researchers of the methods, theories, and data sources used by other scientists to approach similar problems. Scientific research can be guided by existing theories, models and conceptual frameworks that suggest possible answers to questions of interest and point the way of advancement.

A review of relevant literature is a crucial component of any scientific research. Nevertheless, about one half of papers on poverty in Russia have no references whatsoever. The papers in our sample (excluding publications with no references) contain, on average, just 4 citations; a typical social science paper published in the US includes 51 citations (Abt and Garfield 2002) ${ }^{4}$. More than half of all papers with references cited only one or two sources; just 7 papers have more than 10 citations.

\footnotetext{
${ }^{4}$ The average number of references in economic journals has been increasing sharply over the last several decades. Ellison (2001) shows that in 1977/8 a paper published in top four economic journals contained, on average, 15 citations. By 1998 the average number of citations jumped to about 30. Assuming that linear trend, we can estimate that the citations level of Russian publications on poverty corresponds to that level for international economic journals published in 1968.
} 
References to international publications are cited in 30 percent of the papers, while references to Russian sources are included in 40 percent of the publications. Only five publications in the top 20 international economic journals (Kalaitzidakis, et al. 2003) were cited. In particular, Russian researchers cited one paper in: American Economic Review (citation to a paper published in 1977), Econometrica (1980), Quarterly Journal of Economics (1961), Review of Economic Studies (1999), Journal of Human Resources (1996). Out of a total of 280 references to international sources, only three economists were mentioned from the top-100 most-cited economists (Coupe 2003): J. Campbell (4 references), J. Heckman (1 reference), M. Ravallion (3 references). About a third of all citations to Russian sources are based on self-referencing.

Theoretical models, hypotheses, and predictions

Generalized theoretical understanding of a natural or social phenomenon and the development of a theory or a hypothesis that yields a valid prediction about a phenomenon not yet observed is the ultimate goal of science (Friedman 1970, p 6). Scientific theories are representations of certain aspects of reality that can only be approximated by such models. Scientific theories enable researchers to organize and understand earlier observations and to make predictions about future observations and events. In order to be considered scientific a theory must be consistent, parsimonious, correctable, empirically testable or verifiable, useful, and progressive (Root-Bernstein 1984). Any scientific research should be guided by a model or theory that drives the research question, the use of methods, and the interpretation of the results. Theoretical models can be expressed in a form of mathematical equations or as a consistent description of the processes under investigation. A hypothesis originating from theoretical models could be tested against facts. As Popper (1965) noted, the scientific method works primarily through diligent and serious efforts to refute scientific hypotheses.

Poverty studies focusing on behavior of households, individuals, or farms, most often employ theoretical models related to concepts of utility or profit maximization, or both. Such theoretical models lead to corresponding empirical specifications. For 
example, multinomial probability specifications can be derived from utility maximization across a set of discrete choices; models of utility maximization over a continuous outcome might lead to binary and ordered response models, etc. An explicitly specified model allows researchers to establish the causal relations between poverty and various household and/or individual characteristics and, in some cases, uncover the causal mechanism whereby such characteristics affect poverty.

No published research on poverty in Russia contains formal representation of a theoretical model. The majority of authors limit themselves to a description of the processes of interest. Many papers discuss the method of data aggregation or construction of a certain index (e.g., deprivation index) confusing this discussion with a proper description of theoretical models. Two percent of papers outline a certain hypothesis but we have found no papers in our sample that formally test alternative hypotheses.

\section{Sources of empirical data}

The design for data collection, measurement instruments, and methods of data analysis are selected to directly address the research question. In turn, the research question must be formulated in ways that potentially allow for empirical investigation. Scientific beliefs must be evaluated and supported by empirical data. A hypothesis is rationally warranted if a body of evidence and inferences has been provided in support of it. Morgenstern (1963) emphasizes importance of data quality for empirical economic analysis. Price and national accounts statistics, as well as data from household and individual economic surveys are prone to substantial errors. Data for economic analysis are collected from agencies or individuals that have few incentives to provide accurate information. However reliable statistics are essential for scientific decision-making and, therefore, improved performance of the economy as a whole.

More than 40 percent of research articles published in Russia since 1992 are based on aggregated data from Household Budget Survey (HBS) collected by the Federal State Statistics Service of Russia (Goskomstat). HBS is the only official, nationally and regionally representative source of data about living conditions and poverty in Russia. Nevertheless, the HBS unit-record data are not available for public use. Russian 
researchers have to rely on the aggregated statistics published by Goskomstat. The Russia Longitudinal Monitoring Survey (RLMS) initiated in 1992 by the University of North Carolina at Chapel Hill and the World Bank is representative on the national level and for 5 macro regions and covers a sample of 4,000 households (Zohoori et al. 1998). About 20 papers rely on the publicly available RLMS data to analyze poverty in Russia. The National Survey of Household Welfare and Program Participation (NOBUS) is a larger survey of 50,000 households that was conducted by Goskomstat with the support of the World Bank in $2003^{5}$. NOBUS is representative on the national, regional and subregional levels. Data from NOBUS is also publicly available and has been used in four of the papers in our sample.

Empirical data for the majority of publications come from regional, specialized surveys. Fourteen percent of the papers use regional household surveys conducted by the Institute for Social and Economic Studies of the Population (ISESP). Among these are: a longitudinal survey of the living conditions in Taganrog (Katz 2001); a survey of urban households in St. Petersburg and Vyazniki (1997); a household survey of the Volgograd oblast; surveys in Tambov, Nizhnii Novgorod, and Dmitrov (1997). Poverty researchers often rely on data from polls and surveys conducted by the All-Russia Public Opinion Research Center (VCIOM). Data for other studies come from specialized surveys implemented by the Ministry of Labor, local research institutes, and local governments.

Thus, less than 10 percent of all the papers on poverty might claim that their findings can be extended to the national level. Free public access to RLMS and NOBUS data also ensures that studies based on such surveys could be replicated. Neither HBS, nor regional or specialized surveys are accessible by Russian researchers. No paper in our sample presents a clear and detailed description of the sample design methodology, construction of the sample frame, or survey instruments - all of which form a standard set for any empirical publication.

\footnotetext{
${ }^{5}$ NOBUS is a literal translation of the Russian abbreviation "НОБУС” that stands for "Национальное обследование благосостояния населения и его участия в социальных программах”. A detailed description of the survey and the actual data could be found at: http://nobus.worldbank.org.ru.
} 


\section{Data analysis, empirical methodology}

The empirical methods of data analysis aim at linking the economic theory and the actual measurements (Haavelmo 1944). A theoretical model should lead to predictions or a hypothesis and the empirical methods are designed for testing such predictions against facts. In economics, to predict means, in general, to estimate a probable range of economic outcomes of a given policy for given conditions (Marschak 1947). The inherently stochastic nature of economic structural relationships determines the probabilistic character of economic predictions. Since the 1950s, econometric methods have been increasingly employed in all fields of economics (Gilbert 1991). The field of econometrics is large and rapidly growing. This growth is fueled by advances in the theoretical economic models, a sharp increase in computers' processing power, and the advent of large, high quality datasets (Green 2003). Modern empirical economic analysis rarely can be fitted into the classical paradigm of a linear model. Applied econometric research includes non-linear modeling, non- and semi-parametric methods allowing inferences under minimal distributional assumptions, discrete response models, models designed to take into account sample selection, attrition and sample stratification, methods of impact evaluation, and many others. These techniques were developed to provide the tools to answer the increasingly subtle and difficult economic questions that require intricate and complicated formulations.

The formal reporting of empirical results (cross-tabulations and other tables) was found in three-fourths of papers in our dataset. Twenty-five percent of the publications showed just numbers in the text. The statistical significance (standard errors, t- or zstatistics, and p-values) or confidence intervals on the reported statistics (means and percentages) where shown in just five papers (2 percent of the total sample). Another 2 percent of the papers presented significance in the regression output. Thus, only a minute proportion of the papers in our sample can make meaningful inferences from empirical results. An absence of indicators of statistical significance formally invalidates any conclusions drawn from the empirical results.

Regression (OLS) analysis was used in 10 percent of the papers, while 3 percent of the papers used discrete response models. Correlation and transitional matrixes were 
presented in the 4 percent of the papers. It is now commonly accepted that analysis based only on simple means and frequencies without looking at a more complex, multivariate relationships is prone to misinterpretation. Such a low proportion of papers that rely on multivariate techniques implicitly indicates that Russian researchers perceive poverty not as a multidimensional phenomenon, but rather as an outcome produced by a combination of isolated factors. Papers that did apply multivariate methods for data analysis rarely, if ever, used modern econometric techniques. We find no research that employs propensity score matching, difference-in-difference estimators, estimations based on Generalized Methods of Moments, control functions, dynamic panel data, and non- and semiparametric estimators. These econometric models have become standard for any serious poverty analysis over the last decade allowing researchers to obtain robust results that are less restrictive in terms of distributional assumptions and data requirements.

Endogeneity and selection bias are probably the most common problems faced by applied econometricians. Recent decades witnessed an explosive growth in the number of parametric and non-parametric methods to address these issues (e.g., Wooldridge 2002). Research in the area of poverty is plagued by the problems of endogeneity or selection bias. Sample selection bias has deleterious effects on the properties of conventional estimators such as OLS. In many cases, taking into account the selection bias, or endogeneity of explanatory variables, led to a reinterpretation of earlier results (Green 2003). Only one paper in our sample discusses the problem of possible endogeneity of the explanatory variables without actually correcting the results of the analysis. Not only do Russian researchers fail to address these potentially serious problems involving estimation models but they will not even acknowledge their existence, thus rendering the results and conclusions of poverty literature published in Russia over the last 15 years quite questionable ${ }^{6}$. These numbers, however, demonstrate an improvement over the situation in the late 1980's. Alexeev et al. (1992) reviews more than 100 articles published in the leading Russian economic journal "Voprosy Economiki" (Economic Matters) in 1988 and finds no "articles that employ any mathematics, nor any article that attempted to set forth a model, behavioral or otherwise ...”

\footnotetext{
${ }^{6}$ Similar difference in using the multivariate analysis between Russian and Western biologists and medical scientists is reported by Leonov (2002). Thirty percent of papers published in international bio-medical journals relies on multivariate methods, compared to 3 percent of Russian publications.
} 
Evidence-based policy-making is a recent development in the anti-poverty policy process around the world. Impact evaluation has become an important tool for assessing changes in the well-being of individuals, households, communities or firms that can be attributed to a particular project, program or policy. The purpose of impact evaluation is to provide feedback to help improve the design of anti-poverty programs and policies. Based on the results of impact evaluation policymakers can decide whether to expand, modify or eliminate a particular program or policy. Methodology of impact evaluation is developing rapidly. Currently, virtually all international agencies involved in economic development and poverty reduction devote significant resources to evaluation of their projects. Despite the strong advantages of evidence-based policies for poverty reduction, no study in our sample is designed to formally evaluate the effectiveness and impact of national and regional policies.

Table 3 shows the breakdown of empirical economic papers by the type of representation of analytical results for Russia and the US/UK. The US/UK sample is based on 145 empirical works published in top nine international economic journals during 1965 (Thomas 1967) ${ }^{7}$. The difference is startling: 48 percent of empirical papers published in US and UK in 1965 employ regression analysis versus 12 percent of papers published in Russia over the period from 1992 to 2006. The significance statistics are reported in 53 percent of US/UK papers and only in 8 percent of Russian publications. This gap seems even wider if the numbers are adjusted for the availability and costs of computer power that, while extremely expensive in 1965, became virtually costless by the mid-1990s ${ }^{8}$.

\footnotetext{
${ }^{7}$ The "empirical" was defined to cover the presentation of tables of statistical data, the calculation of ratios, means, variances, the construction of frequency distributions, and correlation and regression analysis. The journals are: American Economic Review, Econometrica, Economica, Economic Journal, Journal of Political Economy, Oxford Journal of Economics, Quarterly Journal of Economics, Review of Economics and Statistics, Review of Economic Studies.

${ }^{8}$ We were unable to find the more recent studies that would assess the reporting of the statistical results in the economic journals. However, our own experience in publishing the economic papers and our survey of latest issues of the top economic journals indicate that no empirical economic work can be published without careful and detailed reporting of statistical results, including quite intricate statistical tests.
} 
Interpretation of the results, policy recommendations

The results of any economic inquiry should be reviewed and debated among the professionals and understood by the policymakers in order to be effectively applied in practice. New scientific knowledge is refined through the challenges and criticisms by peer scientists. A critical synthesis of the results of several studies, meta-analysis, becomes a valuable tool for reviewing and evaluating the empirical research and often for reconciling conflicting findings (Stanley 2001). Ultimately, the reliability of scientific studies is determined by the ability to replicate the study results with new data or in different settings. The important question of any scientific investigation is how the findings of a particular study could be extended and generalized over broader population or in different circumstances.

The applied nature of poverty studies implies that its findings must be presented in such a way that it could be disseminated and evaluated by poverty practitioners and the public. When repeated experiments are not feasible - a situation typical of any social science $^{9}$ and of economics in particular - critical reviews and an open professional debate over the new and often contradicting results become necessary to validate the results and to broaden the scientific knowledge.

We find no critical reviews of the poverty studies published in Russia over the last 15 years. As we mentioned in the introduction, no meta-analysis or synthesis of the poverty results has been conducted either. The limited or restricted access to the majority of micro-level datasets could partially explain why no paper in our sample attempts to replicate or verify the results of other studies.

Only a third of the papers offer explicit policy recommendations. While the analysis in a significant proportion of papers in our sample was based on data from regional or local surveys, very few papers attempt to extend the findings to the national level or to show the relevance of the results for the country as a whole.

\footnotetext{
${ }^{9}$ Natural sciences such as Astronomy and Biology (when studying the evolution of species) are also nonexperimental and this also gives rise to discussions, disagreements, disputes and incongruities (Mankiw 2002)
} 


\section{Time trend}

Has the quality of scientific research on poverty in Russia improved over the years? The number of published work on poverty is too small to answer this question with certainty, but we could try to get at least an approximate assessment of this trend.

We design an index reflecting to what degree a particular paper satisfies the principles of scientific research. That index is a simple normalized sum of eight components: whether the paper formulates the research question; cites Russian or foreign sources; presents testable hypotheses; satisfies the standards of reporting the statistical results; and uses any multivariate analysis. The index is zero if none of eight criteria are satisfied and is equal to one if the paper satisfies all these criteria. Figure 2 shows how this quality index changes from 1992 to 2006.

Overall, there is a slight upward trend in the quality of publications on poverty in Russia. But even in the best year (2004) the average publication quality index does not exceed 0.3. When we adjust for the differences in characteristics of publications the quality trend becomes flat ${ }^{10}$.

\section{Conclusions and recommendations}

Scholarly journals are published with a view to promoting advancement of scientific knowledge. Economic journals are the principal medium for exchange of new ideas and they are also primary reference tools for both researchers and policymakers. Economists see economic journals as a means to disseminate their work in the academic community. Such dissemination ensures that scientists working in a particular field are familiar with the current research and informed of the latest methodologies and techniques. For policy practitioners, economic journals offer access to the latest research, while the peer review system ensures the quality and relevance of the work.

\footnotetext{
${ }^{10}$ We regress the quality index on the following characteristics: year of publication, field (economics, sociology), whether the paper is a research piece or a review, a dummy of whether the author is from Moscow or not, dummy variables on the authors' degrees, dummy variables for four journals with largest number of publications on poverty. The results of this descriptive regression are available from authors.
} 
In this paper, we seek to assess whether poverty research literature published in Russia satisfies the general criteria of a scientific publication and if such studies can serve as reliable guidance to the Russian Government as it designs anti-poverty policies. We have reviewed about 250 publications in Russian scientific journals by almost 190 authors over the last 15 years. In this analysis, we consider only formal attributes of these publications, such as the formulation of a research question, availability of references, sources of data, a discussion of theoretical and empirical approaches, reporting of the results, and inferences from the findings.

Our findings indicate that only a small proportion of papers on poverty published in Russia from 1992 to 2006 follow the scientific method of empirical research. The papers are, in general, vague about the main research question; include very few references; present no clear theoretical framework; the empirical methods and techniques used for analysis are outdated; data reporting suffers from lack of precision; most of the inferences made in the analysis are ungrounded; many papers contain no clear policy recommendations. If publications in our sample are representative of poverty research produced in that country, Russian policymakers have very little to learn from it and might be better off disregarding such work completely.

Why is the situation with poverty research in Russia so bleak? Why have good researchers (both in-country as well as those working on the country from abroad), equipped with modern techniques and capable of quality research, not succeeded in making their work stand out in relation to that by their less able colleagues? We think there are several reasons for that. Economics, in the Western understanding of this term, was not introduced in Russia until the early 1990s. Many currently active researchers and politicians received their formal economic education under the Soviet system that emphasized political economy, and provided little training in the micro-, macroeconomics, and econometrics. Policymakers have no means to distinguish the work of inferior quality from high quality studies. And, as our analysis demonstrates, the Russian scientific community has yet to develop a set of internal norms that would ensure a high standard of research. We find that, in fact, methodologically sound works on poverty in Russia are produced by non-economists (e.g. psychologists) who bring the scientific norms of their disciplines to the field of poverty studies. 
Another impediment to higher quality of poverty research is the lack of microlevel data. Only two nationally representative micro-level datasets are currently publicly accessible; most of data from the regional surveys are proprietary. The results of the official surveys conducted by Goskomstat are available only in the aggregate form, with no access to the unit-record data. Clearly, this is not enough for a country the size of Russia with its highly diverse economic, geographic, and ethnic characteristics. Without open access to data, is it impossible to replicate, scrutinize and refine new findings and to filter out poor quality studies. Such lack of data also prevents Russian universities from introducing applied, data-intensive microeconomic courses into their curriculum.

Judging by the number of references to international sources, Russian poverty scientists are barely, if at all, integrated into the world research community ${ }^{11}$. As a result, Russian poverty scientists are inadequately aware of the latest developments in their field. New techniques and methods of economic analysis are taking a long time winning their acceptance and becoming instrumental in their scientific research. The language barrier is probably one of the main obstacles preventing new economic knowledge from informing Russian poverty research.

Finally, none of the journals from our sample employs the double-blind peer review process used by many international journals in selecting and screening articles for publication. It might be difficult for an editor of a scientific journal to evaluate the quality of highly-specialized research on a new subject. It can be impossible for an editor to find mistakes in a complicated piece of scientific work. Subjecting manuscripts to the scrutiny of the anonymous and independent experts in the field would ensure that the published articles meet the standards of the discipline and the general standards of scientific research $^{12}$.

Despite these serious problems, we firmly believe that the quality of scientific research on poverty in Russia could be improved. Developments in the fields of macro-

\footnotetext{
${ }^{11}$ We analyzed the dataset of publications in the top-200 international economic journals from 1985 to 2006 constructed by Das, et al. (2007). Publications that have at least one of the authors affiliated with Russian institutions represent 0.45 percent of the total number of published articles.

${ }^{12}$ The ongoing project of the editors of the Russian physics journals aims at the development of the independent system of quality control for scientific research in physics. The leading Russian physicists and mathematicians emphasize that the lack of the independent assessment of the quality of scientific research is one of the most critical issue for the progress and even the existence of the Russian science. (www.scientific.ru).
} 
economic and fiscal studies, as well as financial economics, demonstrate that in Russia an adequate incentives structure can attract young researchers who have command of the modern techniques and are capable of conducting quality research. In areas where policy outcomes are easily observable, the level of economic discourse in Russia is on par with the international standards. Researchers from several economic institutions, such as the Center for Economic and Finance Research at the New Economic School and various scientific research centers at the Higher School of Economics, as well as others, publish their work in leading international economic journals.

Russian poverty scientists would benefit from better integration in the world research community. Such integration would stimulate constructive scientific dialogue between Russian and international scientists, and expose Russian researchers to the international norms and accepted practices ${ }^{13}$. It would open up the work of Russian researchers for an external debate, thus encouraging a free flow of critical comments.

International cooperation plays a critical role in the development of economic research. The post-communist transformation of economics in the countries of Eastern and Central Europe could be seen as final stages of internationalization of the discipline (Kaase et al. 2003). A large, well-documented body of open knowledge generated by modern economics is within the reach of anyone willing to apply it. Russian poverty economists simply have no choice: either they become part of the international scientific community, or poverty research in Russia remains a substandard, isolated activity without much useful output.

\footnotetext{
${ }^{13}$ In 1963 the economic weekly "Horsodarske Noviny” in Czechoslovakia published the exchange among several prominent economists on the quality of Czechoslovak economic research. The two main reasons explaining the low standards of the economic science in Czechoslovakia were a general lack of economic literature and the impossibility of gaining access to relevant data (Target Area Research and Analysis 1963)
} 


\section{References}

Abt, H., and E. Garfield (2002) "Is the Relationship between Numbers of References and Paper Lengths the Same for All Sciences?” Journal of the American Society for Information Science and Technology, Vol. 53(13): 1106-1112

Alexeev, M., Gaddy, C., and J. Leitzel, (1992) “Economics in the Former Soviet Union”, Journal of Economic Perspectives, Vol. 6(2): 137-148

Bacon, F. (2000). The New Organon, Cambridge University Press.

Brue, S., and C. MacPhee, (1995). "From Marx to Markets: Reform of the University Economics Curriculum in Russia,” Journal of Economic Education, Vol. 26(2): 182-194

Campbell, D. (1974). “Quantitative knowing in action research” Kurt Levin award Address, Society for the Psychological Study of Social Issues, presented at the annual meeting of the American Psychological Association, New Orleans

Coupe, T., (2003). "Revealed Performance: Worldwide Rankings of Economists and Economics Departments, 1990-2000.” Journal of the European Economic Association, Vol. 1(6): 1309-1345

Das, J., Do, T., Sahines, K., and S. Srinivasan (2007). “To Grow is to Know: Economics Research and The Wealth of Countries," mimeo, The World Bank

Einstein, A., and L. Infeld (1938). The evolution of physics. Simon and Shuster, New York

Ellison, G., (2001), "Evolving Standards for Academic Publishing: A q-r Theory", mimeo. Department of Economics, Massachusetts Institute of Technology

Friedman, M., (1970) Essays in Positive Economics, University of Chicago Press, Chicago, IL

Frisch, R. (1933), "Editor's Note”, Econometrica, Vol. 1(1): 1-4

Graham, L., (1973), "Science and Philosophy in the Soviet Union,” Allen Lane

Haavelmo T., (1944) “The Probability Approach in Econometrics," Econometrica, Vol. 12(Supplement) : iii-vi+1-115

Heckman, J. (1979) "Sample Selection Bias as a Specification Error.” Econometrica, Vol. 47(1): 153-161.

Gerschenkron, A., (1978) "Samuelson in Soviet Russia: a Report," Journal of Economic Literature, Vol. XVI: 560-573

Gilbert, R., (1991) "Richard Stone, Demand Theory and the Emergence of Modern Econometrics,” The Economic Journal, Vol. 101: 288-302

Green, W., (2003) Econometric Analysis, fifth edition, Prentice Hall, NJ

Kaase, M., Sparschuh, V., and A. Wenninger (2002) Three Social Science Disciplines in Central and Eastern Europe: Handbook on Economics, Political Science and Sociology (1989-2001), Collegium Budapest and the Social Science Information Centre, Berlin/Bonn/Budapest

Katz, K., (2001). Gender, Work and Wages in the Soviet Union. Palgrave, Hampshire, England

Kalaitzidakis, P., Mamuneas, T., and T. Stengos (2001), "Rankings of Academic Journals and Institutions in Economics," Journal of the European Economic Association, Vol. 1(6): 1346-1366 
King, G., Keohane, R., and S. Verba, (1994). Designing social inquiry: Scientific inference in qualitative research, Princeton: Princeton University Press.

Klugman, J. (1997) Poverty in Russia: Public Policy and Private Responses, World Bank Publications.

Kovzik, A, and M. Watts (2001), "Reforming undergraduate instruction in Russia, Belarus, and Ukraine,” Journal of Economic Education, Vol. 32 (1): 78-92

Lange, O., (1970). Introduction to Economic Cybernetics, Pergamon Press, Oxford

Laudan, L., (1977). Progress and Its Problems, Berkeley, CA: University of California Press.

Leonov, V., (2002), “Statistical Paradigm of Experimental Medicine,” (in Russian) Vestnik Tomskogo Universiteta, Vol. 275: 17-24

Mankiw, G. (2002), Macroeconomics, 5th ed., Worth Publishers: p. 3

Marschak, J., (1947), “Economic Structure, Path, Policy, and Prediction,” The American Economic Review, Vol. 37(2): 81-84

McConnell, C., and S. Brue, (1990), Economics, $11^{\text {th }}$ ed. New York: McGraw-Hill.

Morgenstern, O., (1963), On the Accuracy of Economic Observations. Second edition, Princeton, NJ: Princeton University Press.

MLSD (Ministry of Labor and Social Development) (2000), Prozhitochnui Minimum v Rosiiskoi Federacii (The Subsistence Minimum in Russian Federation), MLSD Moscow, Russia

Pisarev, I. (1959). Methodology Issues of Studying Workers' Living Standards. Moscow, Russia

Popkin B., Mozhina, M., and A. Baturin (1992). “The development of a subsitence income level in the Russian Federation.” Unpublished manuscript, Carolina Population Center, University of North Carolina at Chapel Hill

Popper, K., (1959). The logic of scientific discovery, New York: Basic Books.

Popper, K., (1965). Conjectures and Refutations; The Growth of Scientific Knowledge. Second Edition, New York: Basic Books.

Peirce, C. (1878). "How to Make Our Ideas Clear," Popular Science Monthly, Vol. 12: 286-302

Root-Bernstein, R. (1984) "On Defining a Scientific Theory: Creationism Considered." in Science and Creationism. Ed. Ashley Montagu, New York, Oxford University Press: 64-94

Stokes, D., (1997) Pasteur's quadrant: Basic science and technological innovation, Brookings Institution Press, Washington, DC

Stanley, T., (2001) "Wheat from Chaff: Meta-Analysis as Quantitative Literature Review,” Journal of Economic Perspectives, Vol. 15(3): 131-150

Target Area Research and Analysis (1963) "Revisionism in CS Economics”, Report \#166-134, Czechoslovak Unit

Thomas, J. (1967) “The Reporting of Empirical Work in Economics,” Applied Statistics, Vol. 16(2): 172-176

Wooldridge, J., (2002) Econometric Analysis of Cross-sectional and Panel Data, MIT Press, Cambridge, Massachusetts

World Bank (2005) "Russian Federation: Reducing Poverty through Growth and Social Policy Reform,” The World Bank 
Ziman, J., (2000). Real science: What it is, and what it means. New York: Cambridge University Press.

Zohoori, N., Mroz, T., Popkin, B., Glinskaya, E., Lokshin, M., Mancini, D., Kozyreva, P., Kosolapov M., and M. Swafford, (1998) "Monitoring the Economic Transition in the Russian Federation and its Implications for the Demographic Crisis - the Russia Longitudinal Monitoring Survey", World Development, Vol. 26(11): 19771993 
Table 1: Publications per author, total of 250 articles

\begin{tabular}{lcc}
\hline Publications per author & Number of authors & Percent of authors \\
\hline 1 & 135 & 71.81 \\
2 & 18 & 9.57 \\
3 & 13 & 6.91 \\
4 & 6 & 3.19 \\
5 & 6 & 3.19 \\
6 & 3 & 1.60 \\
7 & 1 & 0.53 \\
8 & 2 & 1.06 \\
9 & 2 & 1.06 \\
11 & 1 & 0.53 \\
13 & 1 & 0.53 \\
\hline Total & 188 & 100.00 \\
\hline \hline
\end{tabular}

Table 2: Author's location

\begin{tabular}{|c|c|c|}
\hline Location & Number of authors & Percent of authors \\
\hline Moscow & 130 & 69.52 \\
\hline Novosibirsk & 7 & 3.74 \\
\hline Saint-Petersburg & 7 & 3.74 \\
\hline Saratov & 6 & 3.21 \\
\hline Nizhnii Novgorod & 4 & 2.14 \\
\hline Ylan-Ude & 4 & 2.14 \\
\hline Vologda & 3 & 1.60 \\
\hline Irkutsk & 3 & 1.60 \\
\hline Kirov & 3 & 1.60 \\
\hline Altaisk & 2 & 1.60 \\
\hline Bryansk & 2 & 1.60 \\
\hline Petrozavodsk & 2 & 1.60 \\
\hline Ul'yanovsk & 2 & 1.60 \\
\hline Prague & 1 & 0.53 \\
\hline Stocholm & 1 & 0.53 \\
\hline Doneck & 1 & 0.53 \\
\hline Ekaterinburg & 1 & 0.53 \\
\hline Mahachkala & 1 & 0.53 \\
\hline Omsk & 1 & 0.53 \\
\hline Rostov-na-Donu & 1 & 0.53 \\
\hline Suktuvkar & 1 & 0.53 \\
\hline Yaroslavl' & 1 & 0.53 \\
\hline N/A & 3 & 1.60 \\
\hline Total & 188 & 100.00 \\
\hline
\end{tabular}


Table 3: Reporting of empirical results: USA 1965 and Russia 1992-2006

\begin{tabular}{lcc}
\hline & USA & Russia \\
& 1965 & $1992-2006$ \\
\hline Parameter estimates & $100 \%$ & $(75 \%)$ \\
Standard errors & $53 \%$ & $8 \%$ \\
Regression analysis & $48 \%$ & $12 \%$ \\
\hline \hline
\end{tabular}

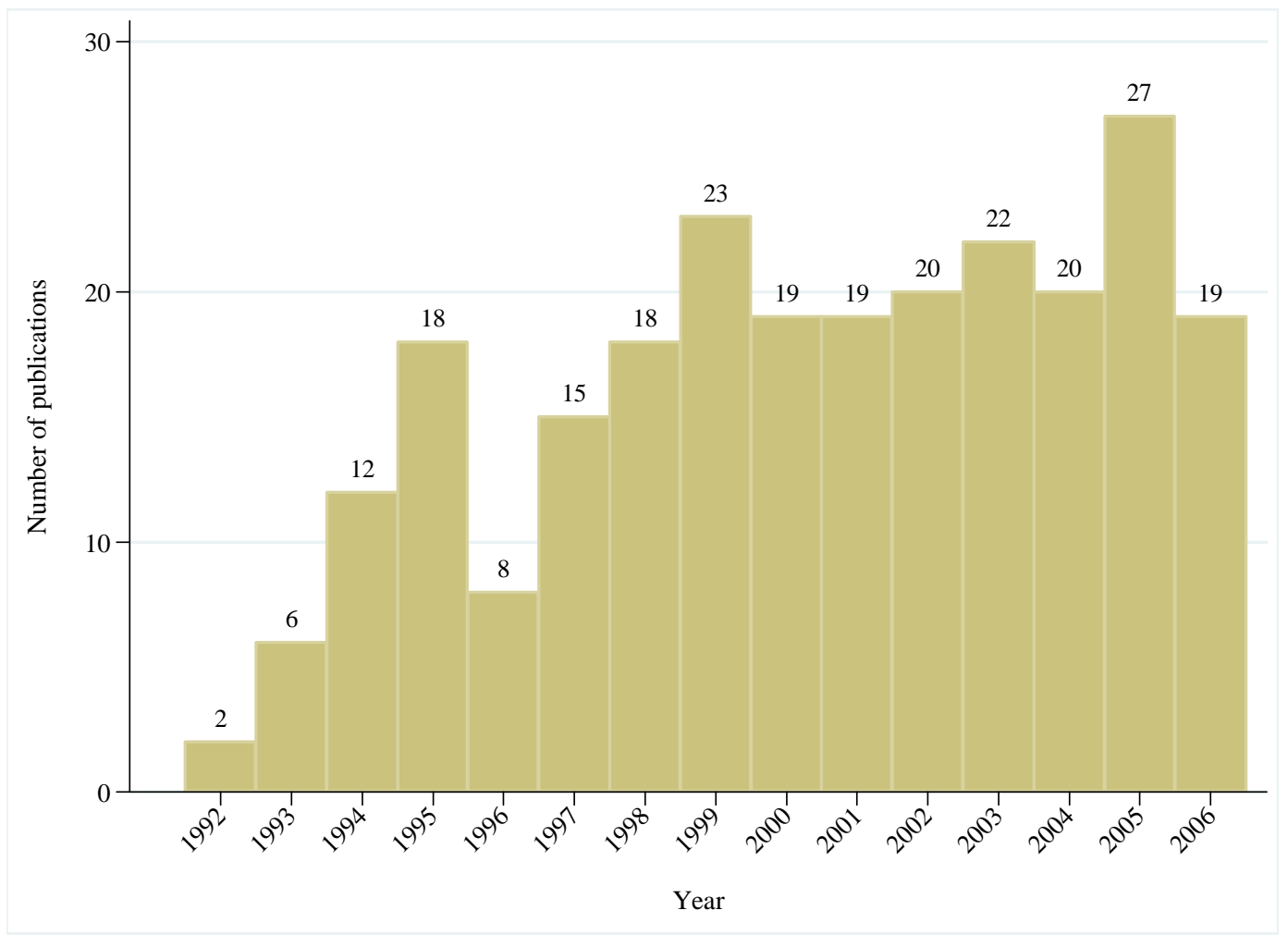

Figure 1: Number of publications on poverty by year 


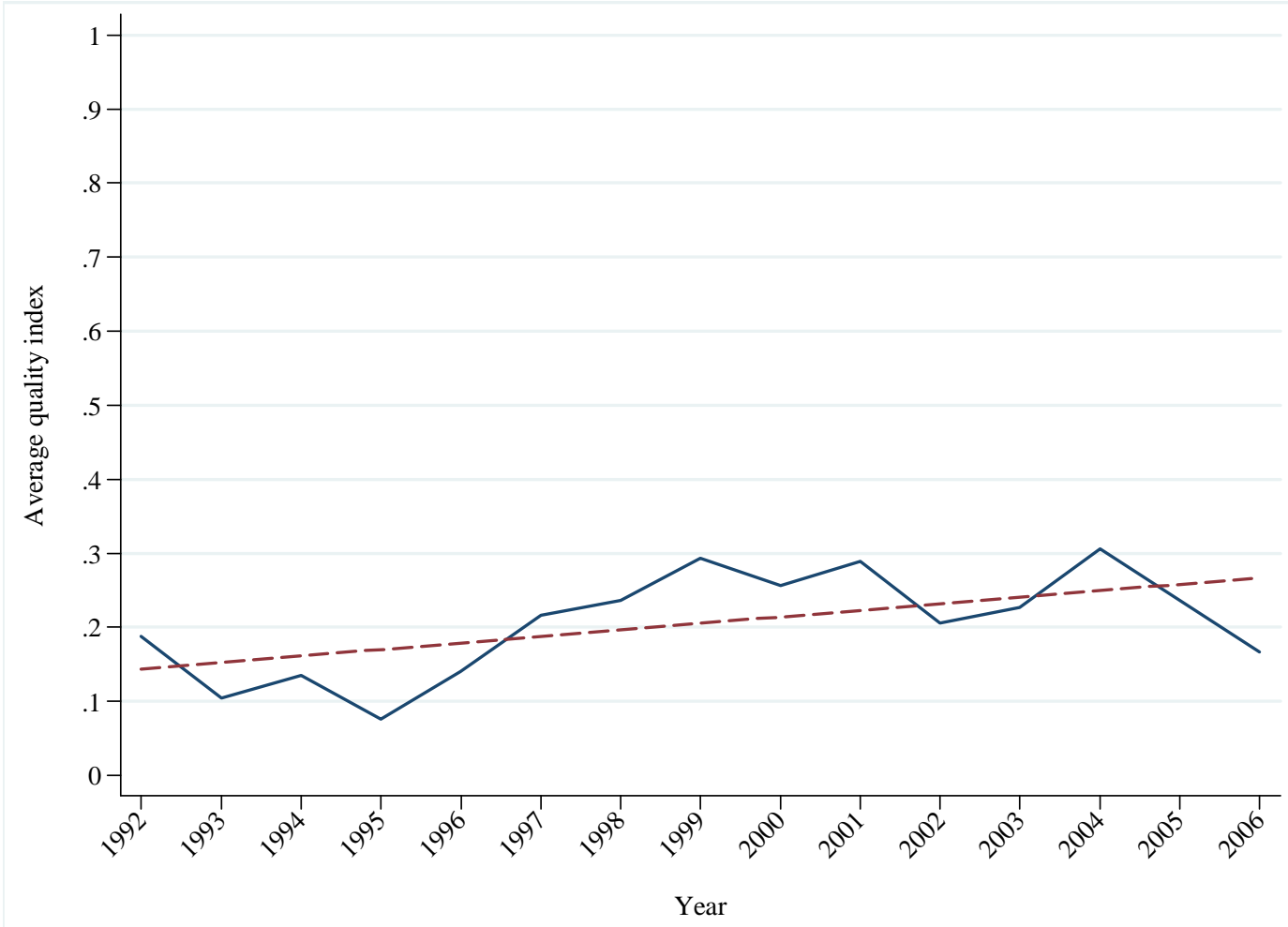

Figure 2: Change in the quality of publications on poverty over time 